\title{
CONCEPTUAL FRAMEWORK FOR THE BEST PRACTICES OF BEHAVIOR-BASED SAFETY PERFORMANCE EVALUATION IN SMALL AND MEDIUM ENTERPRISES (SMES)
}

\author{
Zainudin Awang, Nor Azma Rahlin*, Asyraf Afthanorhan \\ Universiti Sultan Zainal Abidin, Malaysia
}

Employee in small manufacturing enterprise (SMEs) industry suffer high rates of industrial accident than large company as reflected eight times more fatal accidents and $50 \%$ of injuries more likely to occur. With the rising importance of the SMEs, ensuring high levels of safety in SMEs remains a significant issue. This study was undertaken to explore the factors influencing the behaviour-based safety performance in the small medium enterprise. A comprehensive review of the safety literature enabled the invention of the constructs, and items that supported a conceptual behavior-based safety performance evaluation framework. A conceptual framework was adopted based on integration Theory Planned Behavior and Social Exchange Theory. Thus, this study proposed four constructs of behavior-based safety performance evaluation, namely, work ownership and Islamic work ethics, safety climate, and behavior-based safety performance. The best practice of behavior-based safety performance evaluation conceptual framework is proposed for implementation by the SMEs Entrepreneur and practitioner to proactively monitor and manage SMEs safety in the future. The framework will be tested empirically using data collected from SMEs companies in Malaysia. This conceptual framework is one of the alternatives to effectively evaluate safety performance in SMEs, particularly in the Malaysian context.

Key words: behavior-based safety performance, islamic work ethics, employee safety climate, work ownership, small medium enterprises

\section{INTRODUCTION}

Small Medium Enterprises (SMEs) have been recognized as a key player of Malaysian economic development (SME Corporation Malaysia, 2017b). According to SME annual Report (2017b) SME account for $36.6 \%$ of the national GDP. Number of SMEs establishment is 907,065 representation $97 \%$ of the total number of establishment and SMEs offering more than $60 \%$ of employment (SME Corporation Malaysia, 2017a, 2017b).

Instead of significant contribution to the national economy, their contribution to the total occupational accident was substantially high. According to the data published in the SOCSO Annual Report, on average 35 thousand occupational accidents reported in Malaysia annually within five years (SOCSO, 2016). SMEs recorded almost eight times more fatal accident (Tremblay \& Badri, 2018) compared to the large company (Cagno, Micheli, Masi, \& Jacinto, 2013), and non-fatal injuries are roughly $50 \%$ more likely to occur (Guo, Goh, \& Le Xin Wong, 2018; Surienty, 2012). It is further supported by current article which is manufacturing industry in Malaysia is among the most hazardous industries due to its unique nature (Chee, Ramayah, \& Subramaniam, 2018). Additionally, the National Institute of Occupational Safety and Health (NIOSH), reported that $80 \%$ to $90 \%$ of occupational accident identified from Multinational Company (MNC) vendor were categorized under SMEs (Thye, 2010) due to lack of safety culture among middle to lower group employees (Johari, 2013). Consequently, Malaysia had a substantially higher amount of compensation claims from the Social Security Organization (SOCSO). In addition, the financial issues related occupational accident increase with the increasing year (SOCSO, 2016). The statistics of occupational accident for SME are similarly alarming, making an empirical study of this industry become a priority.

\section{PROBLEM STATEMENT}

Workplace safety is a growing concern worldwide (Yuan, $\mathrm{Li}, \mathrm{Xu}, \&$ Huang, 2018). Numerous studies indicated that behavior-based safety are the sustainable reduction methods in reducing occupational related accident (injuries, loss time and severity rate) (Guo et al., 2018; Nunu, Kativhu, \& Moyo, 2017). In addition, several researchers clarified that conceptualizing safety performance as individual behavior prepares researchers with a measurable scale, which is more proximally related to psychological dimensions than accidents or injuries (Christian et al., 2009). Glendon, McNally, Jarvis, Chalmers, \& Salisbury, (2014) justified that behavior-based safety is an effective measure of implementations of psychological research on human behavior in reducing the safety problem. Recently, it was suggested that the implementation of integrative approach of the culture-based and behavior-based safety in small enterprise need a crucial management commitment along with culture change (Nielsen et al., 2013), a good initiative for improving safety of 
front line employees (Choudhry, 2014; Guo et al., 2018), especially in-house employees in small manufacturing enterprise. Behavior based safety performance (BBSP) discussed in this section collectively represent a measurable behavior based actions related to attitudes based perception on management commitment towards safety. The problem, therefore, is how to evaluate safety performance related issues at SMEs through the behavior-based safety performance evaluation framework, which could effectively offer a measure of the behavior-based safety performance in the SMEs. A number of researchers indicated that huge amount of safety climate problems are gradually linked with increased probabilities for experiencing accidents (Ajslev et al., 2017). It also had been documented that safety climate is one of the core indicators of organizational safety outcomes, namely; frequency accidents occur (Huang et al., 2017). However, the effect of ESC on safety performance is not consistent across occupational settings (Clarke, 2006, 2010, 2013).

Considering the above issues, this present study will then extend the knowledge by focus on the antecedents of ESC and BBSP. After more than 35 years, Zohar (1980) safety climate theoretical and applied application study has been explored, and a generic safety climate scale developed by Zohar and Luria (2005) received a huge number of cited papers according to Google scholar (Huang et al., 2017). Despite the extensive evidence concerned on validating safety climate as a leading indicator of safety performance (Zohar, 2010), there have been only a limited number of published studies addressing this issue among SME employee (Hasle \& Limborg, 2006; Tremblay \& Badri, 2018). On the other hand, in spite of much new knowledge about the role of ESC to BBSP, it can be seen that several researchers in the safety related study highlighted the need for antecedence of ESC (Hetherington, 2007; Oah, Na, \& Moon, 2018; Zohar, 2010).

Thus, this present study will look into the antecedent of the ESC. Therefore, this study aims to explore effect of climate-based antecedent on ESC and it link to behavior-based safety performance.

\section{LITERATURE REVIEW}

\section{Conceptual framework of the best practices of behaviour-based safety performance}

A preliminary literature review undertaken on behavior-based safety performance reveals, the best practices of behavior-based safety conceptual framework consists of four constructs; work ownership (WO), Islamic work ethics (IWE), employee safety climate (ESC) and behavior-based safety performance (BBSP).

\section{Behavior-based safety performance}

As shown in the proposed conceptual framework (Figure 1), researchers have chosen behavior-based safe- ty performance as the dependent variable in this study. Behavior-based safety performance refers to the behavior related core safety activities (Christian et al., 2009) required to be fulfilled by employee toward maintaining workplace safety (DeArmond, Smith, Wilson, Chen, \& Cigularov, 2011). Previously, researchers argue that SP was defined as the favorable safety perception of individual compliance and safety involvement (Cheyne, Oliver, Tomás, \& Cox, 2002; Cohen \& Jensen, 1984; DeArmond et al., 2011).

A series of Neal, Griffin and colleagues studies have proposed that two SP dimensions namely, compliance and participation, are directly responsible at the individual level (Griffin \& Neal, 2000; Neal et al., 2000; Neal \& Griffin, 2002; Neal et al., 2000; Neal \& Griffin, 2004, 2006). Prior to a comprehensive work of Neal and Griffin (2006), several safety related studies investigated BBSP based on two dimensions of BBSP either safety compliance and safety participation (e.g.: Agnew et al., 2013; Fernández-Muñiz, Montes-Peón, \& Vázquez-Ordás, 2014; Jiang et al., 2010; Lu \& Yang, 2011) or safety compliance and safety citizenship behavior (Casey \& Krauss, 2013). Therefore, a common BBSP dimension by Neal and Griffin (2000) was adopted as a single dimension.

However, several researchers have identified limited study attempted to investigate two SP dimensions (safety compliance and safety participation) within the individual level (Fugas et al., 2012; Neal et al., 2000; Neal \& Griffin, 2006). Given such complexity, an emergence safety climate perception is a key aspect of BBSP. It is a useful tool to describe about individual employee as a sub-unit of the organization and personal implications of employee. The evidence presented above collectively suggests that there is a need to study individual level BBSP. This present study is one of the first initiatives targeting employee behavior-based safety performance in a small manufacturing enterprise scale and to drive a change in the safety climate in the unique atmosphere of small manufacturing enterprise.

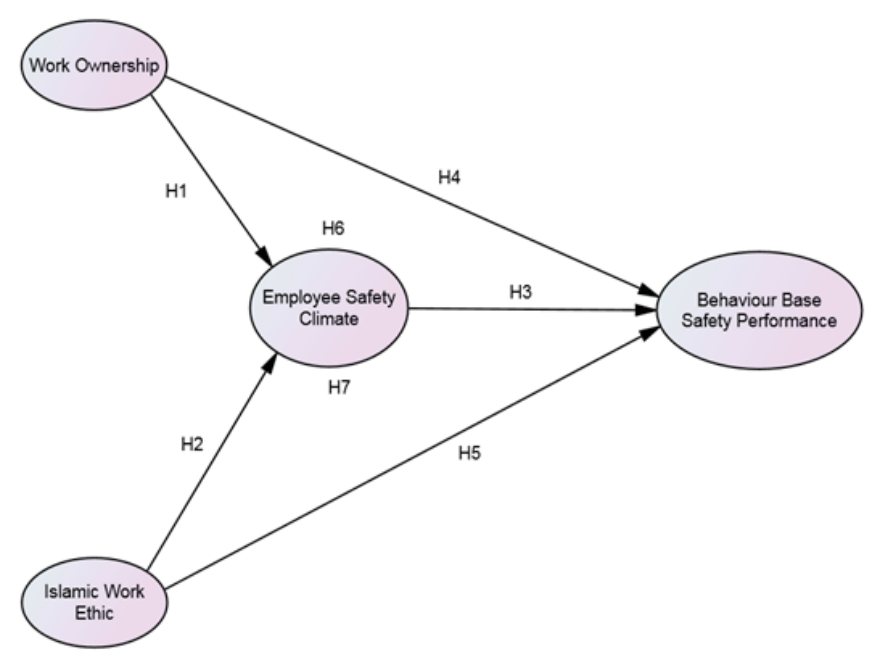

Figure 1: The conceptual framework 


\section{Work ownership}

Reviews on safety climate literature identify work ownership as a climate antecedent (Haro, 2010; Weatherford, 2011; Zohar et al., 2014). Zohar et al., 2014 has point out that most of climate research has focused on inhouse employees, the work ownership-climate relationship has been explained as a social exchange between employee and employer in which employees continually observe and exchange information with their employer as a means for interpreting the work environment. Work ownership is root of Psychological Ownership, where PO can be simplified as employees' feeling like a piece of it is 'theirs' (that is 'It is mine!'). Where is original definition of psychological ownership (PO) is "the state where an individual feel as though the target of ownership or a piece of that target is 'theirs'." (Pierce, Kostova, \& Dirks, 2001; Pierce et al., 2003). Generally, PO has been conceptualized as a motivational factor of attitude and behavior (Brown, Pierce, \& Crossley, 2014; Jussila, Tarkiainen, Sarstedt, \& Hair, 2015). In this case, a piece of target ownership in previous statement best refers to work ownership as a part of job-based psychological ownership. This study, focus on the work ownership as the target of feelings of ownership.

Zohar et al.(2014), has shown that, as late as 2001, Pierce and fellow researchers was using the term 'work ownership' referred to "an occupational circumstance in which one feels as though an aspect of one's work has become part of, or an extension of the self, for example; work becoming "mine" or "ours". Additionally, Zohar et al. (2014) found that work ownership (WO) has a strong relationship with truck safety climate, indicated with the value of Cronbach's Alpha inter correlation of 0.5. A path analysis demonstrated that work ownership contributes to significant effects on the overall model at 0.14 of the regression coefficient. Some other researchers have demonstrated that WO has a significant role in improving safety climate and SP (Haro, 2010; Nor Azma, Munauwar, \& Abdul Halim, 2016; Weatherford, 2011). Taken together, these previous findings suggest a role for WO in promoting individual attitudes, employee perception toward organizational related attitudes (management commitment) and BBSP. However, until now, there is a lack of literature specifically discussing WO in behavior based safety specific on BBSP in small manufacturing enterprise. Therefore, it can be hypothesized that:

\section{Hypothesis}

H1: Work ownership has positive effects on employee safety climate

Instead of positive results of PO on attitudes and behavior, past literature particularly emphasized the role of WO in enhancing management related attitudes and behavior. More specifically, this study expects the positive effects of work ownership on ESC and BBSP among employees in the small manufacturing enterprise. Work ownership might be less obvious when compared with psychological ownership because of the differences in the level of focus. Therefore. This study decided for aggregate work ownership at the individual level that was labeled as work ownership.

In regard to studying antecedents of WO, the present findings add to our understanding of how employees' WO contributes to BBSP. In particular, the present findings contribute to the limited understanding of how wide and deep WO is to BBSP. Therefore, the present study extends the idea of work ownership by Zohar et al. (2014) by remaining true to the original concept of psychological ownership by Van Dyne and Pierce (2004). Then, this research has definitely to its full extent utilized operational definitions in order to describe the meaning and the concept of WO as a part of PO. Since the first ESC antecedent has been discussed the next section will explain how IWE is considered as the second ESC antecedent. Therefore, it can be hypothesized that:

\section{Hypothesis}

H4: Work ownership has positive effects on behavior based safety performance

\section{Islamic work ethic}

Consistent with past research, researcher view Islamic work ethics (IWE) as antecedent to safety climate and behavior-based safety performance. Islamic work ethic consists of precise principles of justice and equity, the dignity of labor, and removal of hardship (Sadek et al., 2010). In order to ensure safety at work, employees are required to comply with safety policy and procedure in the organization such as wearing personal protective equipment and give commitment to their employer toward safety (Rozanah, 2006; Aziz, Afthanorhan, \& Awang, 2016).

By drawing the IWE concept Rahman, Muhamad, and Othman (2006) have been able to show, employees who aim to be real Muslims will dedicate his life to the God, and his/her believe is reflected on attitudes and behavior consistent with the rules and provisions of Islam. To the Muslims, the Islamic religion play a vital role as the reference to shape behavior in the work environment (Ali \& Al-Owaihan, 2008; Abbasi, Rehman, \& Abbasi, 2010; Ali, 1992; Rizk, 2008). Some researchers identified that great Islamic work ethics will postulate several positive impacts a branch of attitudes related outcome, such as, a high organizational commitment among employees (Salahudin, Baharuddin, Abdullah, \& Osman, 2016) and resilience, optimism, self-efficacy, and hope in the organization (Sehhat, Mahmoudzadeh, Ashena, \& Parsa, 2015).

Similarly, Townsend and Thompson (2013) found that a type of religion work ethic might affect the performance of organizational. In 2017, a review article was revealed the linkage between tawhidic paradigm and values in several sectors such as education, financial, telecommunication, public, and healthcare (Suib \& Said, 2017). 
Although there is still no empirical study focusing on the mediating effect of safety climate on the relationships between IWE and behavior-based safety performance, emerging IWE research indicates that a relationship between these variables is plausible. Lately, researchers have shown interest in the study from an Islamic perspective, a number of Islamic researchers have considered the effects of IWE on some related safety climate dimensions; work environment $(b=0.28)$ (Abdus Satta \& Aiza Hussain, 2012), innovation capability ( $b=0.65)$ $(r=0.382, p<0.01) \quad$ (Farrukh eart al., 2015; Kumar \& Rose, 2010). Therefore, it can be hypothesized that:

\section{Hypothesis}

H2: Islamic work ethic has positive effects on employee safety climate

Indeed, some studies provided considerable statistical evidence on IWE and behavior relationship to support this line of argument (Hayati \& Caniago, 2012; Nuñez \& Villanueva, 2011; Sabir, Iqbal, \& Rehman, 2012). Interestingly, longitudinal study carried out by Ariss (2003) on safety ethic found that, in the long term employee involvement effectively reducing in $50 \%$ of safety related behavior such as violation, lost time, and lost days. Besides that, some researchers stated that religion as a core element of IWE and has significant effects on safety behavior (Vitell et al., 2009; Zohar, 1980; Zohar, 2011). Overall, these previous studies show that IWE have a significant connection with attitude and behavior.

In the case of safety at work, Islamic work ethics may have significant effect on safety climate (attitude) and BBSP (behavior-based safety). Thus, one of the greatest challenges in the present study is to link IWE with safety climate and behavior specifically in BBSP research from TPB principle. Therefore, it can be hypothesized that:

\section{Hypothesis}

H5: Islamic work ethic has positive effects on behavior based safety performance

\section{Safety climate}

Zohar (1980) defined SC as molar perceptions that emplo yees share about their work environment. SC research realistically demonstrate the importance of employee perc eption about the organizational priorities as antecedence to safety outcome (Sinclair, Martin, \& Sears, 2010). In this study, researcher view SC as employees' attitude based perceptions to their management commitment and organizational related attitudes toward safety, to increase behavior-based safety performance in the workplace. Rece ntly, it was suggested that the implementation of integra tive approach of the culture-based and behavior-based safety in small enterprise need a crucial management commitment along with culture change (Nielsen et al., 2013), a good initiative for improving safety of front line employees (Choudhry, 2014), especially in-house employees in small manufacturing enterprise.
Empirical evidence shows that management commitment frequently appear as a common underlying theme in prior studies and seems to form an important facet of safety climate measurement (Xia, Zou, Liu, Wang, \& Zhu, 2017). Furthermore, a meta-analysis study supported that SC's underlying management commitment factor was a core predictor of BBSP(Christian et al., 2009). Additionally, Wehbe, Hattab, and Hamzeh (2016) indicated that SC is a critical safety performance indicator. Some other related studies found that management commitment was the core antecedent of safety behavior, indicated by coefficient regression value $(b=0.169, p<0.001)$ (Liu et al., 2015), b=0.19, $p<0.01$ (Vinodkumar \& Bhasi, 2010) and had an indirect effect on occupational injury $(b=0.049, p<0.0001)$ (Liu et al., 2015). Besides that, the successful intervention management commitment in safety climate to drive in increasing employee safety performance (Bronkhorst, Tummers, \& Steijn, 2017).

Moreover, it is practical to utilize at individual/psychological level responses to examine the psychometric properties of a SC measure such as construct validity or measurement equivalency (Cigularov, Adams, Gittleman, Haile, \& Chen, 2013; DeArmond et al., 2011). Additionally, recent evidence suggests that common aspects of psychological safety climate is useful for many types of work environment (Lee et al., 2014). Empirical support of unidimensional SC has been successfully validated (Lee et al., 2014; Zohar, Huang, Jin, \& Robertson, 2014), in many industries such as electrical and utility industry-specific (Huang et al., 2013) and across different industries and companies (Lee et al., 2014). According to (Huang et al., 2017), shorted scale of SC has been mentioned in many publication which most of it use as their measure. Therefore, a short scale SC from Lee et al. (2014) was adapted for this present study.

Overall, various dimensions of SC have been used in different industries, however the SC by Lee et al. (2011) is more suitable for small manufacturing enterprise employee for two reasons. Firstly, the SC instrument at an individual level is applicable to small manufacturing enterprise employee. Secondly, SC which is conceptually concerned with the psychological factor at the individual level under TPB is appropriate to predict BBSP of this present study. Finally, ESC measurement in this study is a TPB mirror comprehensive structure of attitude in Lee et al. (2014) and is appropriate for small manufacturing enterprise.

\section{Relationship between safety climate and safety performance}

Relatively, previous research has investigated the role of ESC and their effects in improving BBSP(Fugas et al., 2012; Goh, Love, Stagbouer, \& Annesley, 2012; Nahrgang, Morgeson, \& Hofmann, 2011) as well as advantages to the organization's performance (Muñiz et al., 2009). A series of meta-analytic studies on SC and BBSP published between 2004 (Cooper \& Phillips, 2004), 2006 
(Clarke, 2006), 2009 (Christian et al., 2009), 2010 (Beus et al., 2010; Clarke, 2010) and 2011 (Nahrgang et al., 2011) have significantly present the art of BBSP studies using comprehensive analytical studies. Interestingly, the meta-analysis of 203 studies found that SC variance comprises of $49.8 \%$ unsafe behaviors (Nahrgang et al., 2011) and empirical study identified that SC is extremely important predictor of BBSP(Barbaranelli, Petitta, \& Probst, 2015; Clarke, 2013; Mullen, Kelloway, \& Teed, 2017). Results from previous survey consistently show that safety climate significantly predict individual safety performance. Nevertheless, the effect of safety climate on safety performance is not consistent across occupational settings ( \& Clarke, 2013; Clarke, 2006, 2010). Therefore, it can be hypothesized that:

\section{Hypothesis}

H3: Safety climate has positive effects on behavior based safety performance

\section{Safety climate as mediator}

A number of authors have considered the mediating effects of SC on safety related behavior studies (Barling, Loughlin, \& Kelloway, 2002; Zohar \& Luria, 2004). Zohar et al. (2014) proof that safety climate mediated relationship between work ownership and employee driving safety performance. A current study found that safety climate mediated the relationship between safety climate antecedent and the three forms of endogenous construct of the study (Tu, Lu, Choi, \& Guo, 2018). Previous study indicated that employee who work for a company with more positive kind of antecedent and climate perceive a small number accident risk (Oah, Na, \& Moon, 2018). While, preliminary study in China reveal that the effect of personality on dangerous driving behavior was mediated by traffic climate (Zhang, Ge, Qu, Zhang, \& Sun, 2018). The above discussion show that, many study has been used employee safety climate as mediation between exogenous construct and endogenous construct, there are strong reasons to hypothesize that:

\section{Hypothesis}

H6: Employee safety climate mediates relationship between work ownership and behavior based safety performance

H7: Employee safety climate mediates relationship between islamic work ethic and behavior based safety performance

\section{Theoretical argument}

The author proposed a conceptual framework that highlighted the need to theoretical interventions to behavior based safety performance conceptual framework with emphasis assigned to climate factors in enhancing behavior based safety performance. This current study provides conceptual framework based on integrating Theory of Planned Behavior (TPB) and Social Exchange Theory
(SET; Afthanorhan, Awang, \& Fazella, 2017; Afthanorhan et al., 2018). Both theoretical rationale and empirical data indicate the presence of significant variation among employees in the organization. Based on SET, both WO and IWE constructs are complimentary climates that represent an antecedent of ESC under climate umbrella.

The TPB idea has been explored in many BBSP research, thus the application of the TPB is no longer unordinary work in BBSP. Many researchers make the TPB known through exploring, adopting a conceptual and theoretical in BBSP(Choudhry, 2014; Fang \& Wu, 2013; Huang et al., 2010, 2007; Jaya Paul, 2014; Tang, 2011; Uryan, 2010; Yong \& Nee, 2011). The TPB is the best theory to describe the relationship at an individual (Ajzen \& Fishbein, 1977) SC and BBSP(Morrow et al., 2014; Uryan, 2010).

As concern for understanding BBSP grew, it became evident that certain aspects of BBSP would develop a strong influence on management process in the workplace. For instance, Kath et al. (2010) is concerned with organizational trust to $\mathrm{SC}$, safety related behavior as social exchange (Hofmann \& Morgeson, 1999; Martínez-Córcoles, Gracia, Tomás, \& Peiró, 2011; Sulastre \& Faridah, 2012), management role and communication effects (Cigularov, Chen, \& Rosecrance, 2010; Dejoy, Della, Vandenberg, \& Wilson, 2010). Much more available literatures that deals with safety also highlights the relevance of social exchange theory (Cui et al., 2013;Mearns, Hope, Ford, \& Tetrick, 2010; Hystada \& Bartoneab, 2013). Interestingly, prominent study by Zohar et al. (2014) used SET to explain causal relationship between WO with SC and BBSP.

Based on SET, both WO and IWE variables are complimentary climates that represent an antecedent of ESC under climate umbrella. Regarding the focus of this present study which is on the employees' psychological attitudes based on perception towards individual level indicator of BBSP, two components of TPB which are known as subjective norm and perceive control have been remove from the model (Afthanorhan et al., 2019; Al-Mhasnah et al., 2018).

Even though, intention is one of the important driving factors of behavior in TPB, but, intention is not justified as mediation due to several reasons as mentioned by previous scholar. For example, Hinsz and Nickell (2015), Wong and Sheth (1985) and Armitage \& Conner (2001) who concluded that intentions fail to predict or inaccurate because they tend to be unstable predictors of behavior. Although, the implementation intention still shows, beneficial effects when the going gets tough, some barrier from personal factors (a low level of competency, a fierce competitor, or strong competing habitual responses) will collapse (Ajzen, 2011).

This study attempts to explain the BBSP variance (endoge nous construct) by using ESC, WO, and IWE functions as an exogenous construct. All determinant variables are bas edon Ajzen's (2006) and Blau's (1964) theoretical model. 


\section{CONCLUSION}

The framework suggests that from a climate perspective, work ownership and Islamic work ethics as well as safety climate may be of equal importance to behavior-based safety performance, leading to the development of the conceptual framework of behavior-based safety performance. For example, an implication of the two antecedent of safety climate may be more likely to lead to safety climate and behavior-based safety performance. Thus, incorporating the notion of climate and behavior will be likely lead to increase predictive ability of behavior-based safety performance models. Further, the framework points to the importance of safety climate as mediator of the relationship between work ownership, IWE and behavior-based safety performance. This conceptual framework is one of the alternatives to empirically evaluate behavior-based safety performance in SMEs, particularly contributes to the literature in the Malaysia context.

\section{Limitation of the study}

In this study, few limitations were encountered. The design of this study approach was made to provide appropriate of the BBSP measures by covering broader array of the small manufacturing enterprise sector.However, in order to increase composite reliability and internal reliability, six items from safety compliance and safety participation were of two sub dimension of BBSP. The results of this current study offers deep understanding and knowledge of two components of BBSP, namely; safety compliance and safety participation, which cannot be captured to the same extent in other studies.Thus, the results pertaining to BBSP should carefully interpret. In addition, in this present research has argue two factors of climate construct, namely; work ownership and Islamic work ethic are relevant in improved employee safety climate and behavior based safety performance. The conceptual model of this study has proven the proposed relationships between climate factors a signifying the SET and TPB theories. However, practical contributions derived from the empirical evidence found in this research should not nullify the theory augmentation.

\section{Future research}

Researchers discuss that of this article generated aspects further, as researchers could provide explanations of the underlying BBSP. As one of earlier study to discourse the effect of climate factors on BBSP in small medium enterprise firms, this article aids as a discussion icebreaker on instrumental BBSP in small medium enterprise companies especially for small manufacturing enterprise. In this study, researchers also acknowledge that further replicated study may consider building on what has been investigated in this research and apply the methodology and findings developed in this research to other relevant construct. The best practices of behavior-based safety performance evaluation in small and medium enterprises (SMEs) should consider multi projection strategies comprises of elements such as enforcement of law and relegation, education or training related safety in workplace, employee engagement and system. Finally, sampling design should be carried out at one specific industry in a boarder range of country geographies. Thus, the results of BBSP specific industry can be added in to the literature of BBSP.

\section{REFERENCES}

Abdus Satta, A., \& Aiza Hussain, R. (2012). Impact of Islamic work ethics (IWEs), reward system (RS) and organizational work environment (OWE) on citizenship behavior of employees (CBE). Science International (Lahore) Journal, 24(4), 513-519.

Afthanorhan, A., Awang, Z., \& Fazella, S. (2017). Perception of Tourism Impact and Support Tourism Development in Terengganu, Malaysia. Social Sciences, 6(3), 106.

Afthanorhan, A., Awang, Z., Salleh, F., Ghazali, P., \& Rashid, N. (2018). The effect of product quality, medical price and staff skills on patient loyalty via cultural impact in medical tourism. Management Science Letters, 8(12), 1421-1424.

Afthanorhan, A., Awang, Z., Rashid, N., Foziah, H., \& Ghazali, P. (2019). Assessing the effects of service quality on customer satisfaction. Management Science Letters, 9(1), 13-24.

Ajzen, I. (2011). Handbook of Theories of Social Psychology: Volume one. (P. A. M. Van Lange, A. W. Kruglanski, \& E. T. Higgins, Eds.). SAGE Publications.

Ajzen, I., \& Fishbein, M. (1977). Attitude-behavior relations: A theoretical analysis and review of empirical research. Psychological Bulletin, 84, 888-918. https://doi. org/10.1037/0033-2909.84.5.888

Ali, A. J. (1992). The Islamic work ethic in Arabia. Journal of Psychology, 126(September 2013), 507. https://doi.or $\mathrm{g} / 10.1080 / 00223980.1992 .10543384$

Ali, A. J., \& Al-Owaihan, A. (2008). Islamic work ethic: A critical review. Cross Cultural Management: An International Journal, 15(1), 5-19. https://doi. org/10.1108/13527600810848791.

AL-Mhasnah, A., Salleh, F., Afthanorhan, A., \& Ghazali, P. (2018). The relationship between services quality and customer satisfaction among Jordanian healthcare sector. Management Science Letters, 8(12), 1413-1420.

Ariss, S. S. (2003). Employee involvement to improve safety in the workplace: An ethical impertive. American Journal of Business, 18(2), 9-16. https://doi.org/http://dx.doi.org/10.1108/19355181200300007

Armitage, C. J., \& Conner, M. (2001). Efficacy of the Theory of Planned Behaviour: A meta-analytic review. The British Journal of Social Psychology / the British Psychological Society, 40(Pt 4), 471-499. https://doi. org/10.1348/014466601164939 
Aziz, M. I., Afthanorhan, A., \& Awang, Z. (2016). Talent development model for a career in Islamic banking institutions: A SEM approach. Cogent Business \& Management, 3(1), 1186259.

Bahari, S. F., \& Clarke, S. (2013). Cross-validation of an employee safety climate model in Malaysia. Journal of Safety Research, 45. https://doi.org/10.1016/j. jsr.2012.12.003

Barbaranelli, C., Petitta, L., \& Probst, T. M. (2015). Does safety climate predict safety performance in Italy and the USA? Cross-cultural validation of a theoretical model of safety climate. Accident Analysis and Prevention, 77, 35-44. https://doi.org/10.1016/j.aap.2015.01.012

Beus, J. M., Payne, S. C., Bergman, M. E., \& Arthur, W. (2010). Safety climate and injuries: An examination of theoretical and empirical relationships. The Journal of Applied Psychology, 95(4), 713-727. https://doi. org/10.1037/a0019164

Bronkhorst, B., Tummers, L., \& Steijn, B. (2017). Improving safety climate and behavior through a multifaceted intervention: Results from a field experiment. Behavioral Public Administration, 103(May 2017), 1-39. https://doi. org/10.1016/j.ssci.2017.12.009

Brown, G., Pierce, J. L., \& Crossley, C. (2014). Toward an understanding of the development of ownership feelings. Journal of Organizational Behavior, 35, 318-338. https://doi.org/10.1002/job

Casey, T. W., \& Krauss, A. D. (2013). The role of effective error management practices in increasing miners' safety performance. Safety Science, 60, 131-141. https://doi. org/10.1016/j.ssci.2013.07.001

Cheyne, A., Oliver, A., Tomás, J. M., \& Cox, S. (2002). The architecture of employee attitudes to safety in the manufacturing sector. Personnel Review, 31(6), 649670. https://doi.org/10.1108/00483480210445953

Choudhry, R. M. (2014). Behavior-based safety on construction sites: A case study. Accident Analysis and Prevention, 70, 14-23.

Christian, M. S., Bradley, J. C., Wallace, J. C., \& Burke, M. J. (2009). Workplace safety: A meta-analysis of the roles of person and situation factors. The Journal of Applied Psychology, 94(5), 1103-1127. https://doi.org/10.1037/ a0016172

Cigularov, K. P., Adams, S., Gittleman, J. L., Haile, E., \& Chen, P. Y. (2013). Measurement equivalence and mean comparisons of a safety climate measure across construction trades. Accident Analysis and Prevention, 51, 68-77. https://doi.org/10.1016/j.aap.2012.11.004

Cigularov, K. P., Chen, P. Y., \& Rosecrance, J. (2010). The effects of error management climate and safety communication on safety: A multi-level study. Accident Analysis and Prevention, 42(5), 1498-1506. https://doi. org/10.1016/j.aap.2010.01.003
Clarke, S. (2006). The relationship between safety climate and safety performance: A meta-analytic review. Journal of Occupational Health Psychology, 11, 315327. https://doi.org/10.1037/1076-8998.11.4.315

Clarke, S. (2010). An integrative model of safety climate: Linking psychological climate and work attitudes to individual safety outcomes using meta-analysis. Journal of Occupational and Organizational Psychology, 83(3), 553-578. https://doi.org/10.1348/096317909X452122

Clarke, S. (2013). Safety leadership: A meta-analytic review of transformational and transactional leadership styles as antecedents of safety behaviours. Journal of Occupational and Organizational Psychology, 86(1), 2249. https://doi.org/10.1111/j.2044-8325.2012.02064.x

Cohen, H. H., \& Jensen, R. C. (1984). Measuring the effectiveness of an industrial lift truck safety training program. Journal of Safety Research, 15(3), 125-135. https://doi.org/10.1016/0022-4375(84)90023-9

Cui, L., Fan, D., Fu, G., \& Zhu, C. J. (2013). An integrative model of organizational safety behavior. Journal of Safety Research, 45, 37-46. https://doi.org/10.1016/j. jsr.2013.01.001

DeArmond, S., Smith, A. E., Wilson, C. L., Chen, P. Y., \& Cigularov, K. P. (2011). Individual safety performance in the construction industry: Development and validation of two short scales. Accident Analysis and Prevention, 43(3), 948-954. https://doi.org/10.1016/j. aap.2010.11.020

Dejoy, D. M., Della, L. J., Vandenberg, R. J., \& Wilson, M. G. (2010). Making work safer testing a Model of Social Exchange and safety management. Journal of Safety Reserach, 41(2), 163-171. https://doi.org/10.1016/j. jsr.2010.02.001

Fernández-Muñiz, B., Montes-Peón, J. M., \& Vázquez-Ordás, C. J. (2009). Relation between occupational safety management and firm performance. Safety Science, 47(7), 980-991. https://doi.org/10.1016/j. ssci.2008.10.022

Fernández-Muñiz, B., Montes-Peón, J. M., \& Vázquez-Ordás, C. J. (2014). Safety leadership, risk management and safety performance in Spanish firms. Safety Science, 70, 295-307. https://doi.org/10.1016/j. ssci.2014.07.010

Fugas, C. S., Silva, S. A., \& Meliá, J. L. (2012). Another look at safety climate and safety behavior: Deepening the cognitive and social mediator mechanisms. Accident Analysis and Prevention, 45, 468-477. https://doi. org/10.1016/j.aap.2011.08.013

Goh, Y. M., Love, P. E. D., Stagbouer, G., \& Annesley, C. (2012). Dynamics of safety performance and culture: A group model building approach. Accident Analysis and Prevention, 48, 118-125. https://doi.org/10.1016/j. aap.2011.05.010 
Griffin, M., \& Neal, A. (2000). Perceptions of safety at work: A framework for linking safety climate to safety performance, knowledge, and motivation. Journal of Occupational Health Psychology, 5(3), 347-358.

Hall, M. E. (2006). Measuring the safety climate of steel mini-mill workers using an instrument validated by structural equation modeling. University of Tennessee.

Haro, E. (2010). An evaluation of perceived and observed safety and productivity in residential construction. Unpublished. Virginia Polytechnic Institute and State University. https://doi.org/10.1017/CBO9781107415324.004

Hayati, K., \& Caniago, I. (2012). Islamic work ethic: The role of intrinsic motivation, job satisfaction, organizational commitment and job performance. Procedia - Social and Behavioral Sciences, 65(ICIBSoS 2012), 1102-1106. https://doi.org/10.1016/j.sbspro.2014.05.148

Hinsz, V. B., \& Nickell, G. S. (2015). The prediction of workers' food safety intentions and behavior with job attitudes and the reasoned action approach. Journal of Work and Organizational Psychology, 31(2), 91-100. https://doi.org/10.1016/j.rpto.2015.03.001

Hofmann, D. A., \& Morgeson, F. P. (1999). Safety-related behavior as a social exchange: The role of perceived organizational support and leader-member exchange. Journal of Applied Psychology. https://doi. org/10.1037/0021-9010.84.2.286

Huang, Y.-H., Chen, P. Y., \& Grosch, J. W. (2010). Safety climate: New developments in conceptualization, theory, and research. Accident Analysis and Prevention, 42(5), 1421-1422. https://doi.org/10.1016/j.aap.2009.12.007

Huang, Y.-H., Leamon, T. B., Courtney, T. K., Chen, P. Y., \& DeArmond, S. (2007). Corporate financial decision-makers' perceptions of workplace safety. Accident Analysis and Prevention, 39(4), 767-775. https://doi. org/10.1016/j.aap.2006.11.007

Huang, Y.-H., Zohar, D., Robertson, M. M., Garabet, A., Murphy, L. A., \& Lee, J. (2013). Development and validation of safety climate scales for mobile remote workers using utility/electrical workers as exemplar. Accident Analysis and Prevention, 59, 76-86. https://doi. org/10.1016/j.aap.2013.04.030

Huang, Y. hsiang, Lee, J., Chen, Z., Perry, M., Cheung, J. H., \& Wang, M. (2017). An item-response theory approach to safety climate measurement: The Liberty Mutual Safety Climate Short Scales. Accident Analysis and Prevention, 103, 96-104. https://doi.org/10.1016/j. aap.2017.03.015

Imanol, N., \& Villanueva, M. (2011). Safety capital: The management of organizational knowledge on occupational health and safety. Journal of Workplace Learning, 23(1), 56-71. https://doi.org/10.1108/13665621111097254

Jaya Paul, A. D. (2014). Predictors of safety compliance among the manufacturing employees in Penfacbic Mill 4. University Utara Malaysia.
Jiang, L., Yu, G., Li, Y., \& Li, F. (2010). Perceived colleagues' safety knowledge/behavior and safety performance: Safety climate as a moderator in a multilevel study. Accident Analysis and Prevention, 42(5), 14681476.

Jussila, I., Tarkiainen, A., Sarstedt, M., \& Hair, J. F. (2015). Individual psychological ownership: Concepts, evidence, and implications for research in marketing. Journal of Marketing Theory and Practice, 23(2), 121-139. https:// doi.org/10.1080/10696679.2015.1002330

Kath, L. M., Magley, V. J., \& Marmet, M. (2010). The role of organizational trust in safety climate's influence on organizational outcomes. Accident Analysis and Prevention, 42(5), 1488-1497. https://doi.org/10.1016/j. aap.2009.11.010

Kumar, N., \& Rose, R. C. (2010). Examining the link between Islamic work ethic and innovation capability. Journal of Management Development, 29(1), 79-93.

Lee, J., Huang, Y., Robertson, M. M., Murphy, L. A., Garabet, A., \& Chang, W.-R. (2014). External validity of a generic safety climate scale for lone workers across different industries and companies. Accident Analysis and Prevention, 63, 138-145. https://doi.org/10.1016/j. aap.2013.10.013

Liu, X., Huang, G., Huang, H., Wang, S., Xiao, Y., \& Weiqing Chen. (2015). Safety climate, safety behavior, and worker injuries in the Chinese manufacturing industry. Safety Science, 78, 173-178.

Lu, C. S., \& Yang, C. S. (2011). Safety climate and safety behavior in the passenger ferry context. Accident Analysis and Prevention, 43(1), 329-341. https://doi. org/10.1016/j.aap.2010.09.001

Martínez-Córcoles, M., Gracia, F., Tomás, I., \& Peiró, J. M. (2011). Leadership and employees' perceived safety behaviours in a nuclear power plant: A structural equation model. Safety Science, 49(8-9), 1118-1129. https:// doi.org/10.1016/j.ssci.2011.03.002

Mearns, K., Hope, L., Ford, M. T., \& Tetrick, L. E. (2010). Investment in workforce health: exploring the implications for workforce safety climate and commitment. Accident Analysis and Prevention, 42(5), 1445-1454. https:// doi.org/10.1016/j.aap.2009.08.009

Morrow, S. L., Kenneth Koves, G., \& Barnes, V. E. (2014). Exploring the relationship between safety culture and safety performance in U.S. nuclear power operations. Safety Science. https://doi.org/10.1016/j. ssci.2014.02.022

Mullen, J., Kelloway, E. K., \& Teed, M. (2017). Employer safety obligations, transformational leadership and their interactive effects on employee safety performance. Safety Science, 91, 405-412. https://doi.org/10.1016/j. ssci.2016.09.007 
Nahrgang, J. D., Morgeson, F. P., \& Hofmann, D. A. (2011). Safety at work: A meta-analytic investigation of the link between job demands, job resources, burnout, engagement, and safety outcomes. The Journal of Applied Psychology, 96(1), 71-94. https://doi.org/10.1037/ a0021484

Neal, A., \& Griffin, M. (2002). Safety climate and safety behaviour. Australian Journal of Management, 27(Special Issues), 67-75. https://doi. org/10.1177/031289620202701S08

Neal, A., \& Griffin, M. A. (2004). Safety climate and safety at work. In The psychology of workplace safety (pp. 15-34). https://doi.org/10.1177/031289620202701S08

Neal, A., \& Griffin, M. A. (2006). A study of the lagged relationships among safety climate, safety motivation, safety behavior, and accidents at the individual and group levels. The Journal of Applied Psychology, 91(4), 946-953. https://doi.org/10.1037/0021-9010.91.4.946

Neal, A., Griffin, M. A., \& Hart, P. M. (2000). The impact of organizational climate on safety climate and individual behavior. Safety Science, 34, 99-109.

Nielsen, K. J., Kines, P., Pedersen, L. M., Andersen, L. P., Andersen, D. R., \& D.R. Andersen. (2013). A multi-case study of the implementation of an integrated approach to safety in small enterprises. Safety Science, 71, Part B, 142-150. https://doi.org/10.1016/j.ssci.2013.11.015

Nor Azma, R., Munauwar, M., \& Abdul Halim, A. M. (2016). The Impact of Psychological Safety Climate on Individual Safety Performance in the Malaysian Manufacturing Small Enterprise: The Role of Psychological Factor and Psychological Work Ownership . World Journal of Management and Behavioral Studies, 4(1), 8-19. https://doi.org/10.5829/idosi.wjmbs.2016.4.1.1324

Oah, S., Na, R., \& Moon, K. (2018). The Influence of Safety Climate, Safety Leadership, Workload, and Accident Experiences on Risk Perception: A Study of Korean Manufacturing Workers. Safety and Health at Work. https://doi.org/10.1016/j.shaw.2018.01.008

Pierce, J. L., Kostova, T., \& Dirks, K. T. (2001). Toward a theory of psychological ownership in organizations. Academy of Management Review, 26(2), 298-310. https://doi.org/10.5465/AMR.2001.4378028

Pierce, J. L., Kostova, T., \& Dirks, K. T. (2003). The state of psychological ownership: Integrating and extending a century of research. Review of General Psychology. https://doi.org/10.1037/1089-2680.7.1.84

Rahman, A., Muhamad, \& N. Othman. (2006). The relationship of Islamic work ethics and organisational commitment: A case analysis. Malaysian Management Review, 41(1), 79-89.

Rizk, R. (2008). Back to basics: An Islamic perspective on business and work ethics. https://doi. org/10.1108/17471110810856992
Sabir, M.S., Iqbal, J.J. \& Rehman, K. (2012). Impact of corporate ethical values on ethical leadership and employee performance. International Journal of Business and Social Science, 3(2), 163-171.

Sadek, D. M., Zainal, N. S., Saiful, M., Mohd, I., Yahya, A. F., Kedah, M., \& Box, P. O. (2010). Service quality perceptions between cooperative and Islamic banks of Britain. Am. J of Economic and Business Administration, 2(1), 1-5.

Salahudin, S. N. bin, Baharuddin, S. S. binti, Abdullah, M. S., \& Osman, A. (2016). The Effect of Islamic Work Ethics on Organizational Commitment. Procedia Economics and Finance, 35(October 2015), 582-590. https://doi. org/10.1016/S2212-5671(16)00071-X

Sehhat, S., Mahmoudzadeh, S. M., Ashena, M., \& Parsa, S. (2015). Positive psychological capital : The role of Islamic work ethics in Tehran Public Organizations. Iranian Journal of Management Studies (IJMS), 8(4), 545-566.

Sigurd W. Hystada, Paul T. Bartoneab, J. E. (2013). Positi ve organizational behavior and safety in the off shore oil industry: Exploring the determinants of positive safety climate. The Journal of Positive Psychology: Dedicated to Furthering Research and Promoting Good Practice, 9(1), 42-53. https://doi.org/10.1080/17439760. 2013.831467

Sinclair, R. R., Martin, J. E., \& Sears, L. E. (2010). Labor unions and safety climate: Perceived union safety values and retail employee safety outcomes. Accident Analysis and Prevention, 42(5), 1477-1487. https://doi. org/10.1016/j.aap.2009.11.003

Suib, F. H., \& Said, M. F. (2017). A Review of Islamic Work Ethics aAnd Spirituality Concepts In Service Industry. Journal of Nusantara Studies, 2(2), 282-294. Retrieved from https://journal.unisza.edu.my/jonus/index. php/jonus/article/view/89

Sulastre, M. Z., \& Faridah, I. (2012). Employers' behavioural safety compliance factors toward occupational, safety and health improvement in the construction industry. Procedia - Social and Behavioral Sciences, 36, 742-751. https://doi.org/10.1016/j.sbspro.2012.03.081

Tang, J. J. (2011). The implementation of occupational safety and health legislation and policies in Hong Kong Schools. University of Nottingham.

Townsend, S. S. M., \& Thompson, L. L. (2013). Implications of the Protestant work ethic for cooperative and mixed-motive teams. Organizational Psychology Review, 4(May), 4-26. https://doi. org/10.1177/2041386613492168

Tu, Y., Lu, X., Choi, J. N., \& Guo, W. (2018). Ethical Leadership and Team-Level Creativity: Mediation of Psychological Safety Climate and Moderation of Supervisor Support for Creativity. Journal of Business Ethics, (2015), 1-15. https://doi.org/10.1007/s10551-018-3839-9 
Uryan, Y. (2010). Organizational safety culture and individual safety behavior: A case study of the Turkish National Police Aviation Department. University of Central Florida.

Van Dyne, L., \& Pierce, J. L. (2004). Psychological ownership and feelings of possession: Three field studies predicting employee attitudes and organizational citizenship behavior. Journal of Organizational Behavior, 25, 439-459. https://doi.org/10.1002/job.249

Vinodkumar, M. ., \& Bhasi, M. (2010). Safety management practices and safety behaviour: Assessing the mediating role of safety knowledge and motivation. Accident Analysis and Prevention, 42(6), 2082-2093. https://doi. org/10.1016/j.aap.2010.06.021

Vitell, S. J., Bing, M. N., Davison, H. K., Ammeter, A. P., Garner, B. L., \& Novicevic, M. M. (2009). Religiosity and moral identity: The mediating role of self-control. Journal of Business Ethics, 88(4), 601-613. https://doi. org/10.1007/s10551-008-9980-0

Weatherford, B. H. (2011). Patient safety: A multi-climate approach to the nursing work environment. Unpublished. https://doi.org/10.1017/CBO9781107415324.004

Wehbe, F., Hattab, M. Al, \& Hamzeh, F. (2016). Exploring associations between resilience and construction safety performance in safety networks. https://doi.org/10.1016/j. ssci.2015.10.006

Wong, J. K., \& Sheth, J. N. (1985). Explaining intention-behavior discrepancy--a paradigm. Advance in Consumer Research, 12, 378-384.
Xia, N., Zou, P. X. W., Liu, X., Wang, X., \& Zhu, R. (2017). A hybrid BN-HFACS model for predicting safety performance in construction projects. Safety Science, 101, 332-343. https://doi.org/10.1016/j.ssci.2017.09.025

Yong, A., \& Nee, H. (2011). Factors affect safety and health behavior of logistics workers in Malaysia: A conceptual framework. In International Conference on Industrial Engineering and Operations Management (pp. 1225-1232). Kuala Lumpur.

Zhang, Q., Ge, Y., Qu, W., Zhang, K., \& Sun, X. (2018). The traffic climate in China: The mediating effect of traffic safety climate between personality and dangerous driving behavior. Accident Analysis \& Prevention, 113, 213-223. https://doi.org/10.1016/j.aap.2018.01.031

Zohar, D. (1980). Safety climate in industrial organizations: Theoretical and applied implications. The Journal of Applied Psychology, 65(1), 96-102. https://doi. org/10.1037/0021-9010.65.1.96

Zohar, D. (2011). Safety climate: Conceptual and measurement issues. Handbook of Occupational Health Psychology, 141-164. https://doi.org/10.1037/10474-006

Zohar, D., Huang, Y., Lee, J., \& Robertson, M. (2014). A mediation model linking dispatcher leadership and work ownership with safety climate as predictors of truck driver safety performance. Accident Analysis and Prevention, 62, 17-25. https://doi.org/10.1016/j.aap.2013.09.005
Paper submitted: 20.12.2018.

Paper accepted: 02.07.2019.

This is an open access article distributed under the CC $B Y-N C-N D 4.0$ terms and conditions. 